\title{
A Viral Disease Occurring in Cultured Carp Cyprinus carpio in Korea
}

\author{
Myung-Joo $\mathrm{Oh}^{1 *}$, Sung-Ju Jung ${ }^{1}$, Tae-Jin $\mathrm{Choi}^{2}$, Hyeong-Rak Kim${ }^{3}$, K. V. Rajendran ${ }^{1}$, \\ Young-Jin Kim ${ }^{1}$, Myung-Ae Park ${ }^{4}$ and Seh-Kyu Chun ${ }^{5}$ \\ ${ }^{1}$ Department of Fish Pathology, Yosu National University, Yosu 550-749, Korea \\ ${ }^{2}$ Department of Microbiology, Pukyong National University, \\ Pusan 608-737, Korea \\ ${ }^{3}$ Department of Food Science and Biotechnology, Pukyong National University, \\ Pusan 608-737, Korea \\ ${ }^{4}$ South Sea Fisheries Research Center, National Fisheries Research \\ and Development Institute, Yosu 550-120, Korea \\ ${ }^{5}$ Korean Institute for Fish Disease Control, Pusan 608-023, Korea
}

(Received March 7, 2001)

\begin{abstract}
A new disease with high mortalities has been occurring in summer scince 1998 in different ages of carp Cyprinus carpio cultured in Korea. The clinical signs of the disease included erratic swimming of moribund fish at the water surface, respiratory distress, presence of thick and foggy mucus covering the body and gills. Dermal ulcers were also noticed in a few cases. Microbiological, parasitological and virological investigations were carried out on the fish samples collected from various localities. Although bacteria and a protozoan parasite were recovered from some fish, their occurrences were not consistent. Histologically, the kidney and spleen showed discernible changes. Inoculation of tissue filtrates from affected fish to various fish cell lines showed cytopathic effects only in FHM. Ultra-thin sections of the infected FHM cells under an electron microscope revealed distinct cytoplasmic virus-like particles with a diameter of $70-80$ $\mathrm{nm}$. Immersion infection trials, using a viral suspension of $10^{3.0} \mathrm{TCID}_{50} / \mathrm{mL}$ obtained from the infected FHM cells, produced 100 and $80 \%$ mortalities in Israel carp and common carp, respectively. This is the first epizootic of viral disease reported among cultured carp in Korea.
\end{abstract}

Key words: viral disease, 5, Carp, Cyprinus carpio, Korea

Carp (Cyprinus carpio), especially common carp and Israel carp, form one of the important cultured fishes in Korea. Annual production of cultured carp is estimated to be about $10,000-12,500$ metric tons, and this constitutes almost $50 \%$ of the current freshwater aquaculture production of the country. However, since 1998, a serious mortality occurred among the cultured carps resulting in a drastic reduction of production. More than $70 \%$ of carp farms in various provinces have suffered heavy economic losses due to the disease outbreak. In this paper, we present a report of the epizootic, based on the microbiological, parasitological and virological investigations. The paper also deals with the electron microscopic evidence of virus-like particles associated with

\footnotetext{
* Corresponding author

E-mail: ohmj@yosu.ac.kr
}

the disease and the experimental infection trials.

\section{Materials and Methods}

\section{Laboratory examination}

Samples of moribund common carp and Israel carp were collected from seven cage culture farms located in various provinces of Korea, and brought to the Fish Pathology Laboratory of Yosu National University. Samples were transported on ice. The 262 sampled fish were immediately subjected to parasitological, microbiological and virological examinations. BHIA (brain heart infusion agar: Difco) and TSA (tryptic soy agar: Difco) were used for bacterial isolation from the gills, liver, spleen, kidney and lesions on the body surface. Kidney and spleen tissues were homogenized with a stomacher, diluted to 1:10 with Hank's BSS and centri- 
fuged at 3,000 $\mathrm{xg}$ for $10 \mathrm{~min}$. The supernatant was filtered through a $0.45 \mu \mathrm{m}$ membrane filter and $100 \mu \mathrm{l}$ aliquots were inoculated onto several fish cell lines. CHSE-214 (chinook salmon embryo), FHM (fathead minnow), EPC (epithelioma papulosum cyprini), and RTG-2 (rainbow trout gonad) cell lines were used in the experiment. Inoculated monolayers, in 24 well tissue culture plates (Corning), were incubated at $20^{\circ} \mathrm{C}$. All these cells were maintained in Dulbeco's minimum essential medium with $10 \%$ FBS (fetal bovine serum: Gibco) and antibiotics (100 I.U. penicillin/mL; $100 \mu \mathrm{g}$ streptomycin/ $\mathrm{mL}, \mathrm{Gibco})$.

\section{Histological studies}

For histological examinations, tissue samples of the kidney, spleen, liver, heart, intestine, gills and muscle were fixed in $10 \%$ NBF (neutral buffered formalin). The tissues were further processed using routine histological techniques and tissue sections were stained with hematoxylin and eosin (H \& E)

\section{Electron microscopy}

For electron microscopy, cells showing cytopathic effect (CPE) were collected by centrifugation at $1200 \times g$ for $10 \mathrm{~min}$. The cell pellets were fixed in $2.5 \%$ glutaraldehyde in phosphate buffer $(0.05 \mathrm{M} ; \mathrm{pH} 7)$; post-fixed in $1 \%$ osmium tertroxide and embedded in Epon 812. Ultra-thin sections were prepared using RMC-MTX ultramicrotome. Sections were stained with lead citrate and uranyl acetate, and examined under Hitachi-7000 electron microscope.

\section{Challenge experiments}

Healthy Israel carp and common carp (11.0-12.0 $\mathrm{cm}$ in total length), collected from localities where the disease outbreak was not recorded, were used for experimental infection trials. Fishes were acclimated to laboratory condition for $1 \mathrm{wk}$ and maintained in plastic containers (50 L capacity, 10 fish each). Filtrates were prepared from FHM cells which showed CPE due to inoculation of the infected tissue filtrate. Fish were given immersion treatment with the filtrates for $1 \mathrm{~h}$. The virus infectivity in the aquaria was adjusted to $10^{3.0} \mathrm{TCID}_{50} / \mathrm{mL}$. Control fishes were given immersion in Hank's balanced salt solution (HBSS) for $1 \mathrm{~h}$. Control and experimental fishes were reared separately in plastic containers and the water temperature was maintained at $20^{\circ} \mathrm{C}$.

\section{Results}

A mass mortality of cultured carps was recorded during the early summer months of the year (June to July) when the water temperature was fairly high (20$24^{\circ} \mathrm{C}$ ). The onset of the disease was found to be sudden and acute, and was found to affect fishes of all

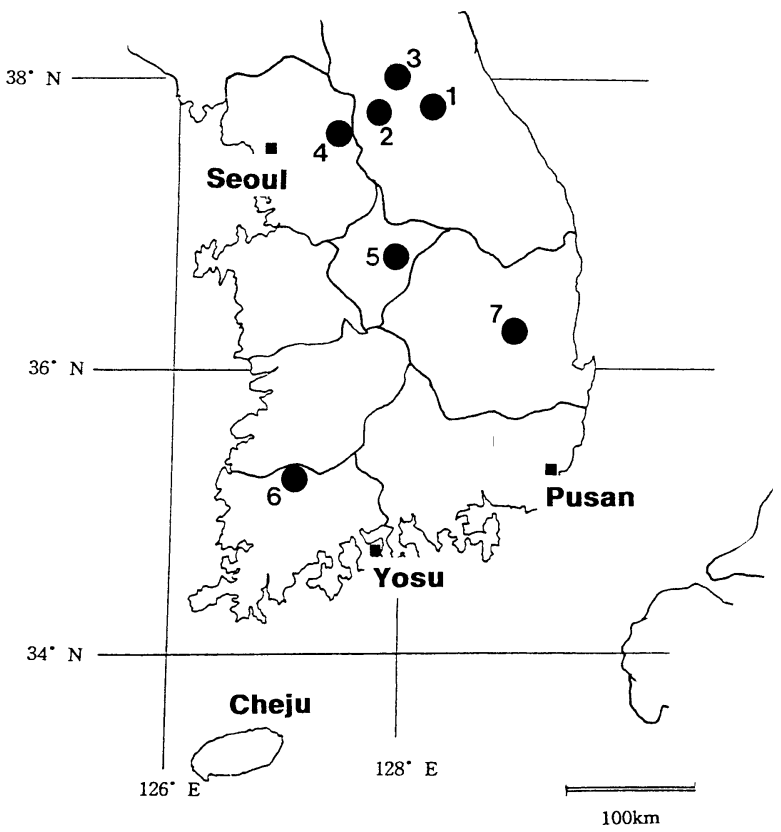

Fig. 1. Sampling locations $(\lambda)$ of carps Cyprinus carpio during 1998-2000 in Korea.

1. Soyang Lake (Kangwon Province), 2. Chunchon Lake (Kangwon Province), 3. Hwachon Lake (Kangwon Province), 4. Chongpyong Lake (Kyunggi Province), 5. Chungju Lake (Chungbuk Province), 6. Jangsung Lake (Chunnam Province), 7. Andong Lake (Kyungbuk Province).

ages. Seven carp farms surveyed during the period (Fig. 1) recorded 60-95\% mortalities within a period of 3-7 days. Moribund fish swam at the surface with their heads up and showed obvious signs of respiratory distress. Upon gross examination, the fish showed discoloration, thick foggy mucus covering over the body and gills. Dermal lesions on the body surface were also noticed in a few fish (Fig. 2).

Preliminary laboratory examinations revealed bacterial infections in fish collected from two net-cage farms. Aeromonas hydrophilla, Flavobacterium columnare and Pseudomonas sp. were isolated from the gills and lesions on the body surface of these fish. However, fish from one farm showed Myxobolus sp. infection in their gills. Bacterial infections were found mostly in fishes which showed dermal lesions on the body. Histological sections of the kidney, spleen and liver showed moderate to heavy necrotic changes. Vacuolization and nuclear condensation were prominent in all the samples examined (Fig. 3). However, no pathogens could be detected in the tissue sections by light microscopy. Analysis of samples from all the seven localities showed consistent pathological changes.

Tissue filtrate from infected fish, upon inoculation to various cell lines, produced cytopathic effect (CPE) in FHM monolayer at 3-5 days post-inoculation (Fig. 4). The entire cell sheet showed complete lysis within a 


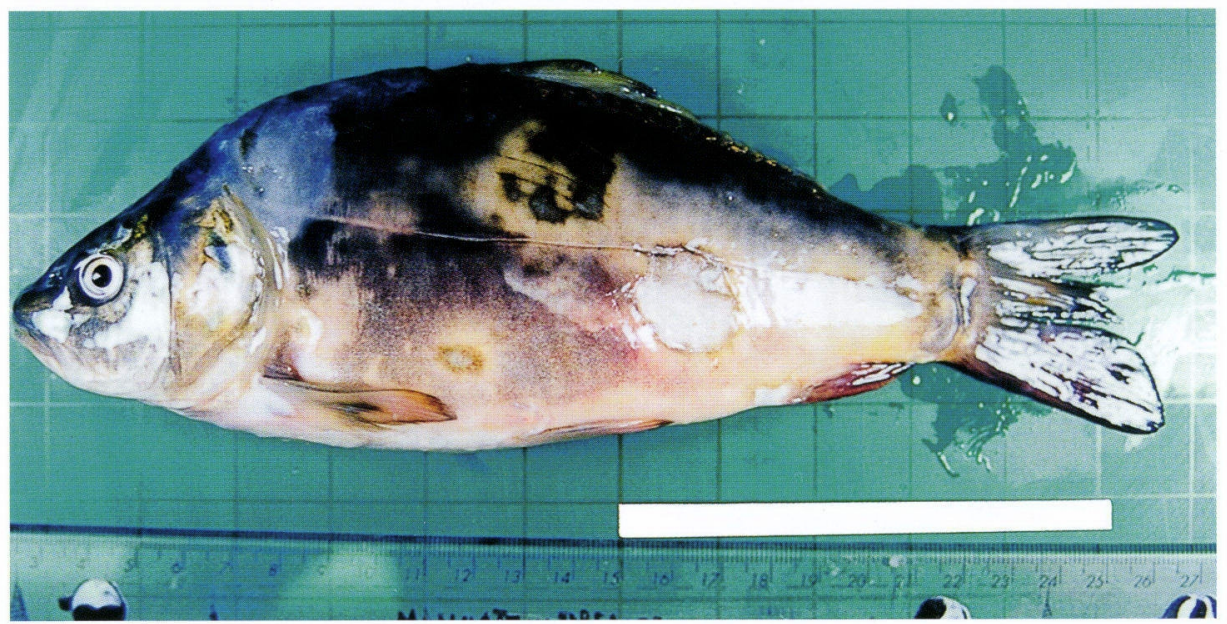

Fig. 2. Diseased Cyprinus carpio showing body discoloration and thick foggy mucus covering the body surface. (Scale bar $=10 \mathrm{~cm})$.

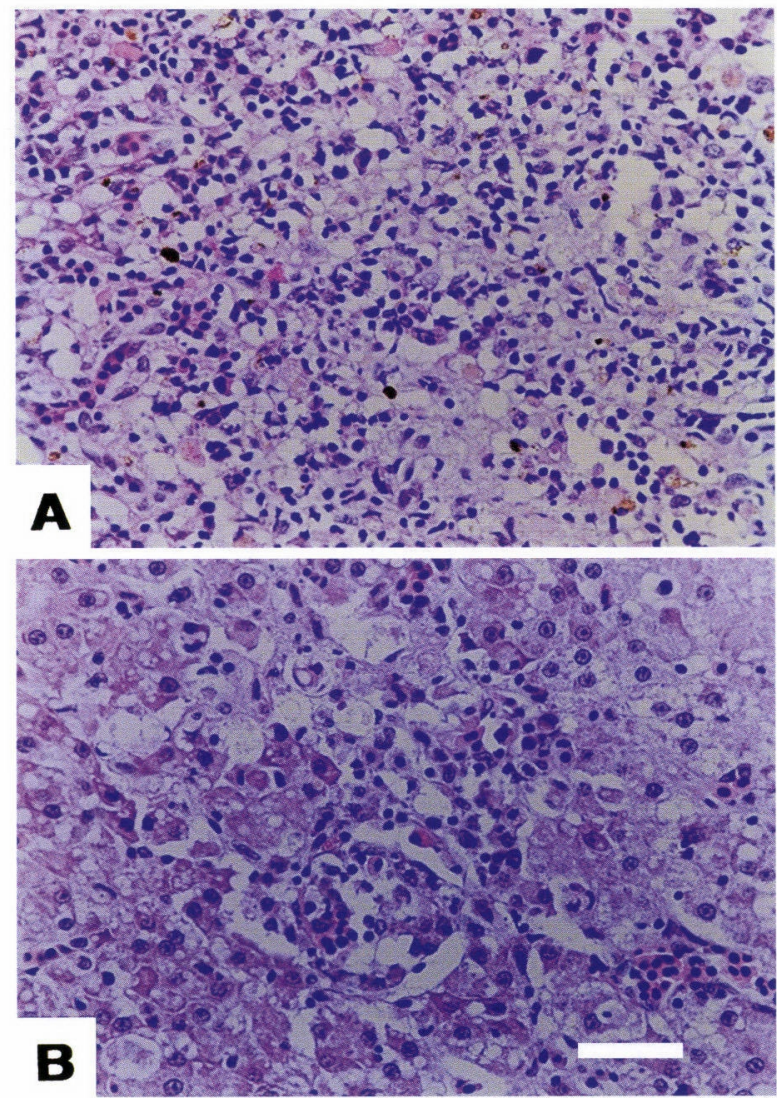

Fig. 3. Histological section of (A) spleen and (B) liver of naturally infected fish showing necrotic changes. (Scale bar $=25 \mu \mathrm{m})$.

period of 15 days. However, other cell lines used in the experiments, CHSE-214, RTG-2 and EPC, did not show any CPE. All samples subjected for virus isolation (10 samples for each area) showed similar effects on the cell lines. The FHM cells which showed CPE were subjected to electron microscopic examinations. Ultra-thin sections of the infected FHM cells revealed distinct, virus-like particles in the cytoplasm. The virions mea-
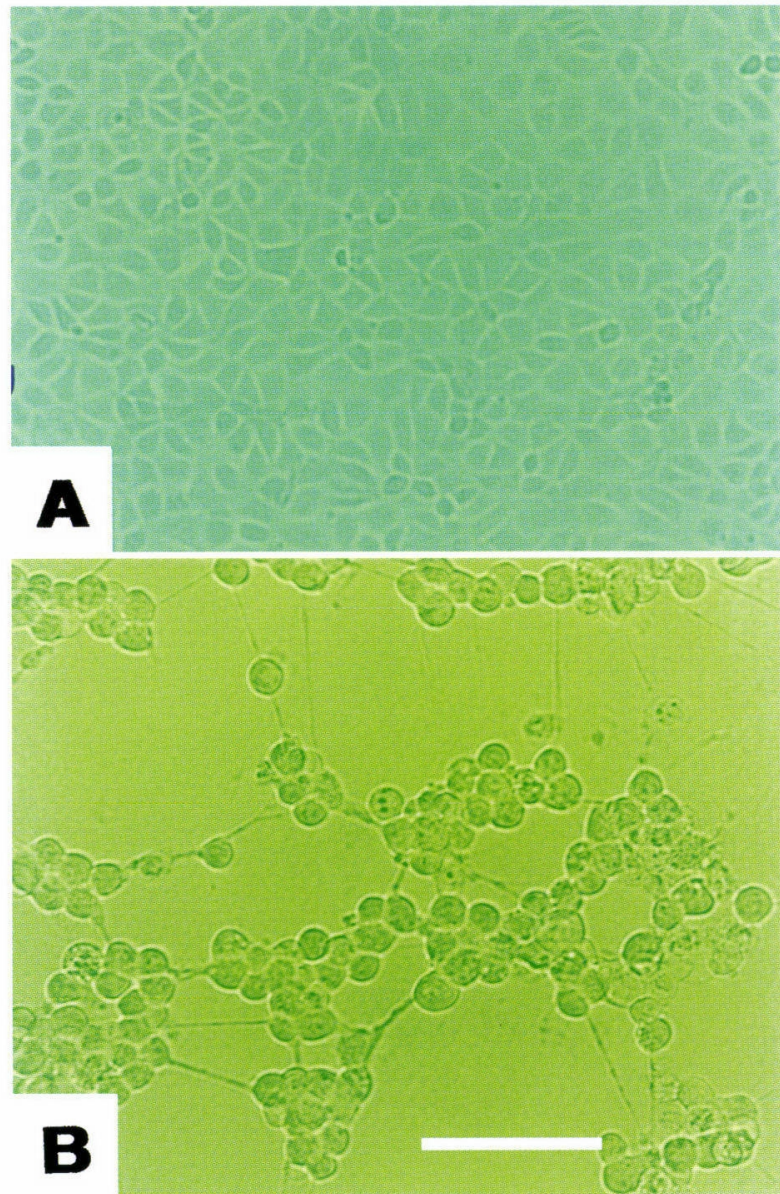

Fig. 4. Cytopathic effect produced by inoculation with the tissue filtrate in FHM cells (7 days post-inoculation). A: normal cells, B: infected cells. (Scale bar $=50 \mu \mathrm{m}$ ).

sured 70-80 nm in diameter (Fig. 5).

Experimental infection trials, using the filtrate prepared from infected FHM cells, exhibited that Israel carp and common carp were highly susceptible to the infection. In the experimentally infected Israel carp and common carp, cumulative mortality reached $100 \%$ and 


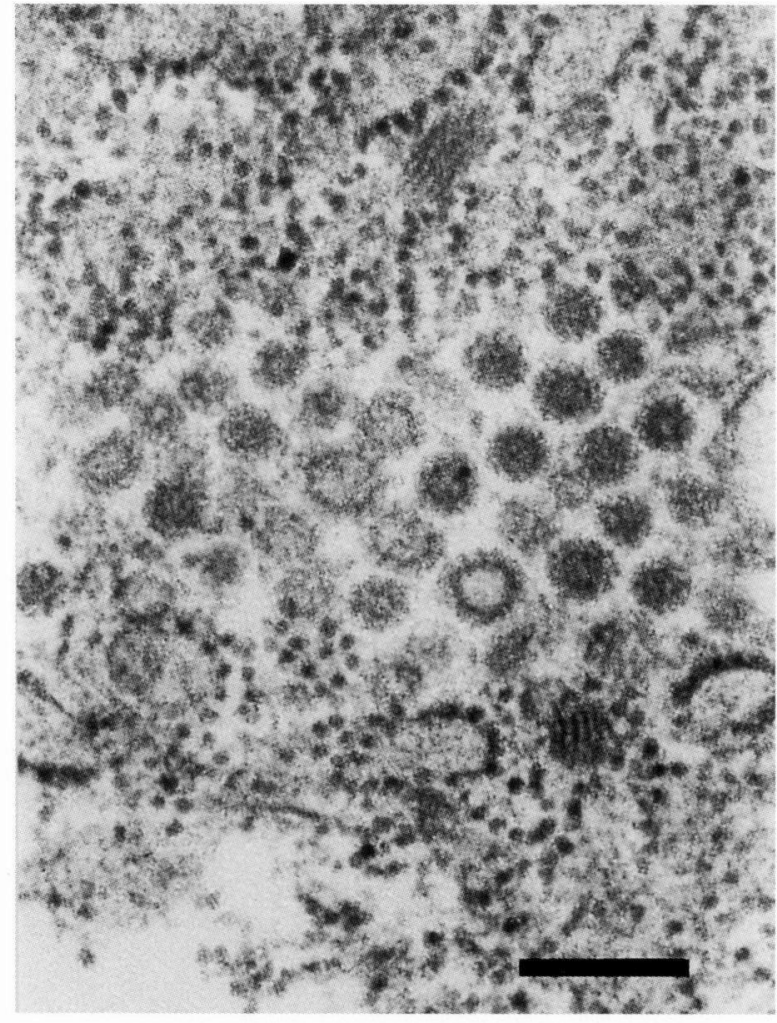

Fig. 5. Electron micrograph of virus-like particles observed in the FHM cells. (Scale bar $=200 \mathrm{~nm}$ ).

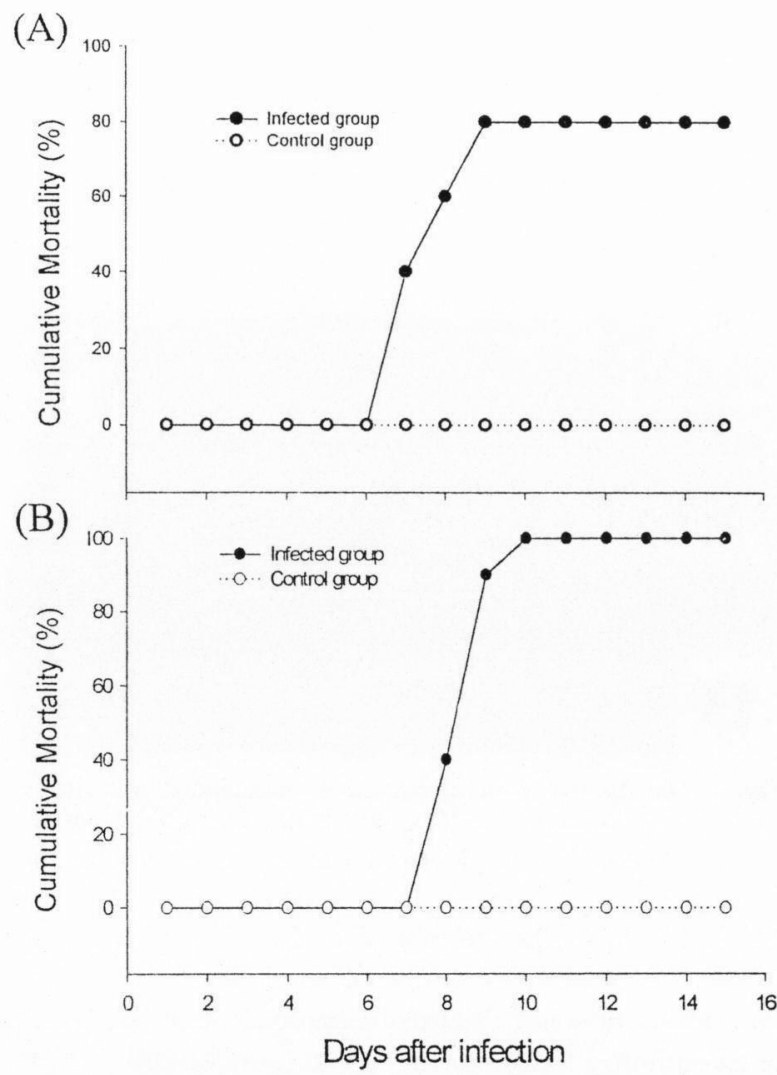

Fig. 6. Cumulative mortality of common carp (A) and Israel carp (B) observed in the experimental infection trials.
$80 \%$, respectively, in 15 days of post-infection (Fig. 6). All the dead and moribund fishes showed similar clinical signs as those of naturally infected fish. The infected fishes showed discoloration, thick foggy mucus covering over the body and showed dermal lesions on the body surface. The control group in both experiments did not show any mortality. Inoculation of tissue filtrate, prepared from the experimentally infected fishes, to various cell lines produced CPE only in FHM cells. Further, these FHM cells under an electron microscope revealed the virus-like particles similar to that observed in the case of naturally infected fishes.

\section{Discussion}

Nature of the disease outbreak and the results of present laboratory analyses indicated a viral etiology to the disease occurring in cultured carps. Although bacterial pathogens such as $A$. hydrophilla, F. columnare and Pseudomonas sp. and a protozoan parasite, Myxobolus sp. were noticed in a few samples, no relationship between the presence of these bacteria or the parasite and the disease outbreak could be elucidated. All the samples collected from different localities revealed consistent results with respect to the histopathological manifestations, CPE on FHM cells inoculated and electron microscopic observation. Further, infection trials using Israel carp and common carp revealed a distinct similarity with those of the Ç"Ç†Ç spontaneous infection in the susceptibility of the fish host and clinical signs of the disease.

Infections with several viruses, such as IHNV (infectious hematopoietic necrosis virus), IPNV (infectious pancreatic necrosis virus), OMV (Oncorhynchus masou virus), RVS (retrovirus of salmonid), CSV (chum salmon reovirus) and an iridovirus-like virus, have been reported from cultured fishes in Korea (Oh and Jung, 1999; Jung and Oh, 2000). However, the present disease of carp differs from all the previously reported viral diseases in many respects. Furthermore, the present disease was restricted to the freshwater aquaculture system, and this forms the first viral disease outbreak of epizootic proportion reported among cultured carp in Korea.

Disease outbreaks in cultured carp, however, have been recorded from other parts of the world. Oyamatsu et al. (1997) reported a contagious edema caused by a pox-like virus, which resulted in mass mortalities of cultured colored carp in Japan. However, the contagious edema differs from the present disease in the clinical manifestations and also in the non-culturable nature of the pox-like viral pathogen. Another disease outbreak has also been reported in carp, Cyprinus carpio from Japan (Kaku et al., 1999). They have reported an epizootic ulcerative disease in carp and identified a bacterial pathogen, Aeromonas salmonicida, as the causative agent. In the present study, however, we found a virus 
as the primary causative agent and the bacterial infections were thought as secondary infections. Recently, Miyazaki et al. (2000) reported a corona-like virus associated with dermal ulceration (ana-aki-byo) on C. carpio in Japan, and they also recorded the involvement of a bacterial pathogen. The present case differs from the ana-aki-byo in the characteristics of the primary pathogen including the specific susceptibility of FHM cell lines to the virus. Nevertheless, further studies on the causative virus including characterization and infection mechanisms are required.

\section{Acknowledgment}

We appreciate Dr. T. Miyazaki, Mie University, for his helpful advise. We are also thankful to Mr. HeongSik Oh, Gea-Chang Sohn and II-Han Kim for their providing samples. This study was supported by a grant from the Ministry of Maritime Affairs and Fisheries, Korea.

\section{References}

Jung, S.J. and M.J. Oh (2000): Iridovirus-like infection associated with high mortalities of striped beakperch, Oplegnathus fasciatus (Temmink et Schlegel), in southern coastal areas of the Korean peninsula. J. Fish Dis., 23, 223-226.

Kaku, Y., Y. Yamada and H. Wakabayashi (1999): Characterization of atypical Aeromonas salmonocida isolated from an epizootic ulcerative disease in carp (Cyprinus carpio). Fish Pathol., 34, 155-162.

Miyazaki, T., H. Okamoto, T. Kageyama and T. Kobayashi (2000): Viremia-assocaited ana-aki-byo, a new viral disease in color carp Cyprinus carpio in Japan. Dis. Aquat. Org., 39, 183-192.

Oh, M.J. and S.J. Jung (1999): Viral diseases of fish in Korean mariculture. In "Proceedings of fifth international symposium on the efficient application and preservation of marine biological resources" (ed. by J. A Shin, S. J. Jung, J. M. Kim and W. K. Lee). Oct. 1999, Yosu, Korea. pp25-32.

Oyamatsu, T., N. Hata, K.Yamada, T. Sano and H. Fukuda (1997): An etiological study on mass mortality of cultured colorcarp juveniles showing edema. Fish Pathol., 32, 8188. 